\title{
Amputation and phantom limb pain
}

\author{
Ronald Melzack ${ }^{1}$ and Joel Katz ${ }^{2}$ \\ ${ }^{1}$ McGill University \\ ${ }^{2}$ York University
}

Phantom limbs occur in $95-100 \%$ of amputees who lose an arm or leg. The phantom limb is usually described as having a tingling feeling and a definite shape that resembles the somatosensory experience of the real limb before amputation. It is reported to move through space in much the same way as the normal limb would move when the person walks, sits down, or stretches out on a bed. At first, the phantom limb feels perfectly normal in size and shape, so much so that the amputee may reach out for objects with the phantom hand, or try to step on to the floor with the phantom leg. As time passes, however, the phantom limb begins to change shape. The arm of leg becomes less distinct and may fade away altogether, so that the phantom hand or foot seems to be hanging in mid-air. Sometimes, the limb is slowly 'telescoped' into the stump until only the hand or foot remain at the stump tip (Solonen, 1962). However, the neural basis of the phantom does not disappear. Injury of the stump years or decades after fading or telescoping may suddenly produce a phantom as vivid and full-sized as that felt immediately after amputation (Cohen, 1944).

Amputation is not essential for the occurrence of a phantom. After avulsion of the brachial plexus of the arm, without injury to the arm itself, most patients report a phantom arm (the 'third arm') which is usually extremely painful (Wynn-Parry, 1980). Even nerve destruction is not necessary. About $95 \%$ of patients who receive an anaesthetic block of the brachial plexus for surgery of the arm report a vivid phantom, usually at the side or over the chest, which is unrelated to the position of the real arm when the eyes are closed but 'jumps' into it when the patient looks at the arm (Melzack \& Bromage, 1973). Similarly, a spinal anaesthetic block of the lower body produces reports of phantom legs in most patients (Bromage \& Melzack, 1974), and a total section of the spinal cord at thoracic levels leads to reports of a phantom body including genitalia and many other body parts in virtually all patients (Bors, 1951; Conomy, 1973; Melzack \& Loeser, 1978).

\section{Phantom limb phenomena}

The most astonishing feature of the phantom limb is its incredible reality to the amputee (Simmel, 1956), which is enhanced by wearing an artificial arm or leg; the prosthesis feels real, 'fleshed out'. Amputees in whom the phantom leg has begun to 'telescope' into the stump, so that the foot is felt to be above floor level, report that the phantom fills the artificial leg when it is strapped on and the phantom foot now occupies the space of the artificial foot in its shoe (Riddoch, 1941). Patients who have undergone a cleavage of the forearm stump muscles, to permit them to hold objects, report that the phantom hand also has a cleavage and lies appropriately in the stump (Kallio, 1950).

The remarkable reality of the phantom is reinforced by the experience of details of the limb before amputation (Katz \& Melzack, 1990, 2003). For example, the person may feel a painful bunion that had been on the foot or even a tight ring on a phantom finger. Still more astonishing is the fact that some amputees who receive drugs that produce the tremor of tardive dyskinesia report a tremor in the phantom (Jankovic \& Glass, 1985).

Phantoms of other body parts feel just as real as limbs do. Heusner (1950) describes two men who underwent amputation of the penis. One of them, during a 4-year period, was intermittently aware of a painless but always erect phantom penis. The other man had severe pain of the phantom penis. Phantom bladders and rectums have the same quality of reality (Bors, 1951; Dorpat, 1971). The bladder may feel so real that patients, after a bladder removal, sometimes complain of a full bladder and even report that they are urinating. Patients with a phantom rectum may actually feel that they are passing gas or faeces. Menstrual cramps may continue to be felt after a hysterectomy. A painless phantom breast, in which the nipple is the most vivid part, is reported by about $25 \%$ of women after a mastectomy and $13 \%$ feel pain in the phantom (Kroner et al., 1989). 
The reality of the phantom body is evident in paraplegics who suffer a complete break of the spinal cord. Even though they have no somatic sensation or voluntary movement below the level of the break, they often report that they still feel their legs and lower body (Bors, 1951; Burke \& Woodward, 1976). The phantom appears to inhabit the body when the person's eyes are open and usually moves co-ordinately with visually perceived movements of the body. Initially, the patient may realize the dissociation between the two when he sees his legs stretched out on the road after an accident yet feels them to be over his chest or head. Later, the phantom becomes coordinate with the body, and dissociation is rare.

Descriptions given by amputees and paraplegics indicate the range of the qualities of experience of phantom body parts (Bors, 1951; Katz \& Melzack, 2003, 1990). Touch, pressure, warmth, cold and many kinds of pain are common. There are also feelings of itch, tickle, wetness, sweatiness and tactile texture. Even the experience of fatigue due to movement of the phantom limb is reported (Conomy, 1973). Furthermore, male paraplegics with total spinal sections report feeling erections and paraplegic women describe sexual sensations in the perineal area. Both describe feelings of pleasure, including orgasms (Bors, 1951; Money, 1964; Verkuyl, 1969).

One of the most striking features of the phantom limb or any other body part, including half of the body in many paraplegics, is that it is perceived as an integral part of one's self. Even when a phantom foot dangles 'in mid-air' (without a connecting leg) a few inches below the stump, it still moves appropriately with the other limbs and is unmistakable felt to be part of one's body-self. So, too, the multiple phantoms sometimes felt after an amputation are all part of the self (Lacroix et al., 1992). The fact that the experience of 'self' is subserved by specific brain mechanisms is demonstrated by the converse of a phantom limb, the denial that a part of one's body belongs to one's self. Typically, the person, after a lesion of the right parietal lobe or any of several other brain areas (Mesulam, 1981) denies that a side of the body is part of him or herself and even ignores the space on that side (Denny-Brown et al., 1952). From these cases it is evident that the brain processes which underlie the experience of our bodies must impart a special signal that provides the basis for experience of the self. When these brain areas are lost, the person denies that a part of the body belongs to the self. Even when a hand, for example, is pinched hard so that the patient winces or cries out, s/he still denies that the hand is hers/his.

There is convincing evidence that a substantial number of people who are born without all or part of a limb (congenital limb deficiency) feel a vivid phantom pain of the missing part. These phantoms are reported by children (Poeck, 1964; Weinstein et al., 1964; Melzack et al., 1997) as well as by adults (Saadah \& Melzack, 1994; Brugger \& Regard, 1997), and possess all the properties of phantoms described by amputees. Furthermore, the phantom may sometimes not appear until maturity, usually after a minor injury or surgery of the deficient limb (Saadah \& Melzack, 1994).

The innate neural substrate implied by these data does not mean that learning experience is irrelevant. Learning obviously underlies the fact that people's phantoms assume the shape of the prosthesis, and people with a deformed leg or a painful corn often report, after amputation, that the phantom is deformed or has a corn. That is, sensory inputs play an important role in the experience of the phantom limb. Heredity and environment clearly act together to produce the phenomena of phantom limbs.
These observations can be summarized in the form of four propositions (Melzack, 1989) which derive from the data:

1. The experience of a phantom limb has the quality of reality because it is produced by the same brain processes that underlie the experience of the body when it is intact.

2. Neural networks in the brain generate all the qualities of experience that are felt to originate in the body; inputs from the body may trigger or modulate the output of the networks but are not essential for any of the qualities of experience.

3. The experience of the body has a unitary, integrated quality which includes the quality of the 'self', that the body is uniquely one's own and not that of any other individual.

4. The neural network that underlies the experience of the body-self is genetically determined but can be modified by sensory experience.

\section{A hypothesis for phantom limbs: the neuromatrix}

The anatomical substrate of the body-self, Melzack (1989) proposes, is a network of neurons that extends throughout widespread areas of the brain (which has been demonstrated in imaging studies by Ingvar \& Hsieh, 1999). He has labelled the network, whose spatial distribution and synaptic links are initially determined genetically, and are later sculpted by sensory inputs, as a 'neuromatrix'. Thalamocortical and limbic loops that comprise the neuromatrix diverge to permit parallel processing in different components of the neuromatrix and converge repeatedly to permit interactions between the output products of processing. The repeated cyclical processing and synthesis of nerve impulses in the neuromatrix imparts a characteristic pattern or 'neurosignature'.

The neurosignature of the neuromatrix is imparted on all nerve impulse patterns that flow through it; the neurosignature is produced by the patterns of synaptic connections, which are initially innate and then modified by experience, in the entire neuromatrix. All inputs from the body undergo cyclical processing and synthesis so that characteristic patterns are impressed on them in the neuromatrix. Portions of the neuromatrix are assumed to be specialized to process information related to major sensory events (such as injury) and may be labelled as neuromodules which impress subsignatures on the larger neurosignature.

\section{Phantom limb pain}

About $70 \%$ of amputees suffer burning, cramping and other qualities of pain in the first few weeks after amputation. Even seven years after amputation, $50 \%$ still continue to suffer phantom limb pain (Krebs et al., 1985; Jensen \& Nikolajsen, 1999). Why is there so much pain in phantom limbs? Melzack (1989) proposes that the active neuromatrix, when deprived of modulating inputs from the limbs or body, produces an abnormal signature pattern that subserves the psychological qualities of hot or burning, the most common qualities of phantom limb pain. Cramping pain, however, may be due to messages from the neuromatrix to produce movement. In the absence of the limbs, the messages to move the muscles may become more frequent and 'stronger' in the attempt to move a part of the limb. The end result of the output message may be felt as cramping muscle 
pain. Shooting pains may have a similar origin, in which the neuromatrix attempts to move the whole limb and sends out abnorma patterns that are felt as pain shooting down from the groin to the foot. The origins of these pains, then, lie in the brain. Sensory inputs, however, clearly contribute to the phantom: stimulation of the stump or other body sites often produces sensations referred to the phantom limb (Katz \& Melzack, 2003).

Surgical removal of the somatosensory areas of the cortex or thalamus generally fails to relieve phantom limb pain (White \& Sweet 1969). However, the new theory conceives of a neuromatrix that extends throughout selective areas of the whole brain, including the somatic, visual and limbic systems. Thus, to destroy the neuromatrix for the body-self which generates the neurosignature pattern for pain is impossible. However, if the pattern for pain is generated by cyclical processing and synthesis, then it should be possible to block it by injection of a local anesthetic into appropriate discrete areas that are hypothesized to comprise the widespread neuromatrix. Data obtained in rats have shown that localized injections of lidocaine into diverse areas, such as the lateral hypothalamus and the dentate gyrus (McKenna \& Melzack, 1992) produce striking decreases in experimentally produced pain, including the pain in an animal model of phantom limb pain (Vaccarino \& Melzack, 1991).

(See also 'Pain', 'Pain assessment' and 'Pain management'.)

\section{REFERENCES}

Bors, E. (1951). Phantom limbs of patients with spinal cord injury. Archives of Neurology and Psychiatry, 66, 610-31. Bromage, P.R. \& Melzack, R. (1974). Phantom limbs and the body schema. Canadian Anesthetists' Society Journal, 21, 267-74.

Brugger, P. \& Regard, T. (1997). Illusory reduplication of one's own body: phenomenology and classification of autoscopic phenomena. Cognitive Neuropsychiatry, 2, 19-38.

Burke, D.C. \& Woodward, J.M. (1976). Pain and phantom sensation in spinal paralysis. Handbook of Clinical Neurology, 26, 489-99.

Cohen, H. (1944). The mechanism of viscera pain. Transactions of the Medical Society of London, 64, 65-99.

Conomy, J.P. (1973). Disorders of body image after spinal cord injury. Neurology, 23, 842-50.

Denny-Brown, D., Meyer, J.S. \& Horenstein, S. (1952). The significance of perceptual rivalry resulting from parietal lesion. Brain, 75, 433-71.

Dorpat, T.L. (1971). Phantom sensations of internal organs. Comprehensive Psychiatry, 12, 27-35.

Heusner, A.P. (1950). Phantom genitalia. Transactions of the American Neurological Association, 75, 128-31.

Ingvar, M. \& Hsieh, J.C. (1999). The image of pain. In: P.D. Wall \& R. Melzack (Eds.). Textbook of Pain 4th edn. (pp. 215-33). Edinburgh: Churchill Livingstone.

Jankovic, J. \& Glass, J.P. (1985). Metoclopramide-induced phantom dyskinesia. Neurology, 35, 432-5.

Jensen, T.S. \& Nikolajsen, L. (1999). Phantom pain and other phenomena after amputation. In P.D. Wall and R. Melzack (Eds.). Textbook of pain 4 th edn. (pp. 799-814). Edinburgh: Churchil Livingstone.

Kallio, K.E. (1950). Phantom limb of forearm stump cleft by kineplastic surgery. Acta Chirurgica Scandinavica, 99 $121-32$.

Katz, J. \& Melzack, R. (1990). Pain 'memories' in phantom limbs: review and clinical observations. Pain, 43, 319-26.

Katz, J. \& Melzack, R. (2003). Phantom limb pain. In: J. Grafman \& I.H. Robertson (Eds.). Handbook of neuropsychology (pp. 205-30). Amsterdam: Elsevier.

Krebs, B., Jensen, T.S., Kroner, K., Nielsen, J. \& Jorgensen, H.S. (1985). Phantom limb phenomena in amputees seven years after limb amputation. In H.L. Fields, R. Dubner \& F. Cervero (Eds.). Advances in pain research and therapy, Vol. 9 (pp. 425-9). New York: Raven Press.

Kroner, K., Krebs, B., Skov, J. \& Jorgensen, H.S. (1989). Immediate and long-term phantom breast syndrome after mastectomy: incidence, clinical characteristics and relationship to pre-mastectomy breast pain. Pain, 36, 327-34.

Lacroix, R., Melzack, R., Smith, D. \& Mitchell, N. (1992). Multiple phantom limbs in a child. Cortex, 28, 503-7.

McKenna, J.E. \& Melzack, R. (1992). Analgesia produced by lidocaine microinjection into the dentate gyrus. Pain 49, 105-12.

Melzack, R. (1989). Phantom limbs, the self and the brain. Canadian Psychology, 30 1-16.

Melzack, R. \& Bromage, P.R. (1973).

Experimental phantom limbs. Experimental Neurology, 39, 261-9.

Melzack, R., Israel, R., Lacroix, R. \& Schultz, G. (1997). Phantom limb in people with congenital limb deficiency or amputation in early childhood. Brain, 120, 1603-20.

Melzack, R. \& Loeser, J.D. (1978). Phantom body pain in paraplegics: evidence for a central 'pattern generating mechanism'. Pain, 4, 195-210.

Mesulam, M.M. (1981). A cortical network for directed attention and unilateral neglect. Annals of Neurology, 19, 309-15.
Money, J. (1964). Phantom orgasm in the dreams of paraplegic men and women. Archives of General Psychiatry, 3, 373-82. Poeck, K. (1964). Phantoms following amputation in early childhood and in congenital absence of limbs. Cortex, 1 , 269-75.

Riddoch, G. (1941). Phantom limbs and body shape. Brain, 64, 197-222.

Saadah, E. S.M. \& Melzack, R. (1994). Phantom limb experiences in congenital limb-deficient adults. Cortex, 30, 479-85. Simmel, M. (1956). On phantom limbs. Archives of Neurology and Psychiatry, 75, 69-78.

Solonen, K.A. (1962). The phantom phenomenon in amputated Finnish war veterans. Acta Orthopaedica Scandinavica, Suppl. 54, 7-37.

Tasker, R.A.R., Choinière, M., Libman, S.M. \& Melzack, R. (1987). Analgesia produced by injection of lidocaine into the lateral hypothalamus. Pain, 31, 239-48.

Vaccarino, A.L. \& Melzack, R. (1989). Analgesia produced by injection of lidocaine into the anterior cingulum bundle of the rat. Pain, 39, 213-19.

Vaccarino, A.L. \& Melzack, R. (1991). The role of the cingulum bundle in self-mutilation following peripheral neurectomy in the rat. Experimental Neurology, 111, 131-4.

Verkuyl, A. (1969). Sexual function in paraplegia and tetraplegia. Handbook of Clinical Neurology, 4, 437-65.

Weinstein, S., Sersen, E.A. \& Vetter, R.T. (1964). Phantoms and somatic sensation in cases of congenital aplasia. Cortex, I, 276-90.

White, J.C. \& Sweet, W.H. (1969). Pain and the neurosurgeon. Springfield, IL: C.C. Thomas.

Wynn-Parry, C.B. (1980). Pain in avulsion lesions of the brachial plexus. Pain, 9, 41-53. 